\title{
ANALYSING THE RESULTS FIELD TESTS OF AN EXPERIMENTAL SEEDER WITH SEPARATE INTRODUCTION OF SEEDS AND FERTILIZERS
}

\author{
MUBARAK ADUOV, SAULE NUKUSHEVA, ESENALIKASPAKOV, \\ KAZBEKISENOV \& KADIRBEK VOLODYA
}

Saken Seifullin Kazakh Agrotechnical University, Astana, Kazakhstan

\begin{abstract}
The task of agricultural production is obtaining high yields, and the basis for this is laid down during sowing. The analysis has shown that in the existing seed colters, despite their diversity, the fertilizer is mainly introduced together with the seeds, but for better formation of the root system and better sprouting, separate introduction of seeds and fertilizers is preferred; with that, the fertilizers should be introduced below the depth of seeding. In this regard, the authors studied the design and the technology used in the existing seed-fertilizer seeder and working organs, held searching experiments, made two variants of the experimental seed colters, performed theoretical calculations $\left(R_{T}\right)$ and laboratory and field studies. An experimental unit that consisted of a tractor and a seeder with experimental seed colterswas tested, while the reference seeding was made with a standard seeder. It has been found that the tractive resistance of the experimental seeder exceeds the tractive resistance of the standard seeder by $5-10 \%$ in the stubbles, and by $1.5-5 \%$ in a plowed field; the quality of work of the experimental seeder is superior to that of the standard seeder: in terms of seeding uniformity - by $3.56 \%$; and in terms of plants distribution across the feeding area - by $3 \%$. Analysis during the three years of the research has shown that the yield in the plot seeded with an experimental seed fitted with colters with a soil compactor and a seed guide is higher on average by $21.2 \%$ than the yield in the plot planted with a standard seeder, and the yield from a plot sown with seeder with experimental seed colters without a soil compactor is higher on average by $10.5 \%$ than the yield from a plot sown with a standard seeder.

KEYWORDS: Tractive Resistance, Separate Introduction, Stubble Drill, Planting Depth, Introduction of Seeds \& Fertilizers \& Colters
\end{abstract}

Received: Mar 13, 2019; Accepted: Apr 03, 2019; Published: Jul 04, 2019; Paper Id.: IJMPERDAUG201958

\section{INTRODUCTION}

Kazakhstan is considered to be one of the greatest grain-producing countries in the world, where strong and hard wheat varieties with high content of gluten are cultivated, which are in great demand in the global market. However, analysis of the technology of cultivating agricultural crops shows that the increase in the yield of agricultural products, the cost reduction caused by introducing new varieties are measured in all countries by a few percents, usually not more than $10-15 \%$. More significant results of increasing efficiency may be obtained through developing new genuine technologies and means of mechanization.

Today in Kazakhstan, the demand in agricultural machinery and processing equipment is satisfied through imports. Agricultural machinery and process equipment are imported without regard to the soil-and-climatic factors, adaptation to the local conditions, and proper maintenance, thereby exacerbating the problems in this area. 
In this regard, the production of domestic agricultural equipment remains today a very important problem.

There are various seed-fertilizer seeders with the introduction of seeds and fertilizers to the same soil horizon [1] (Matyuchkov \& Azarov, 2002). The disadvantage of these seeders is that fertilizers are used only in the case when the humidity of the seeding layer of the soil contributes to the formation of the secondary root system and is above the layer of fertilizers [2] (Aduov, Kapov \& Nukusheva 2017). In other cases, in case of insufficient moisture in the seeding layer, the root system of plants is below the layer of the introduced fertilizers that are not used in the initial period of plant development [3] (Celik \& Altikat 2013). In other seed designs, such as John Deer 1895, TUME, the fertilizers, and the seeds are introduced separately to different soil horizons [4] (Kryhcin N 2003). Implementation of this method requires additional colters, which increases the cost of the seeders and impairs their penetrability in the stubbles.

In this regard, the authors aimed at creating an experimental model of the seeder and performing laboratory and field tests. The novelty of the suggested seeder is in re-engineering the seed boxes and the sealing part of the cultivator seeders that are widely used in Northern Kazakhstan [5] (Aduov, Matyushkov \& Nukusheva 2015). Two variants of experimental colters have been developed. The first colter variant [6] (Aduov, Kapov, Nukusheva, Kaspakov \& Volodja 2017) includes a tubular rack, a shovel, and the two side plates secured to the shovel rack; the surfaces are made along the exponential curve, run from the bottom up, but in the opposite direction from the direction of the colter movement. A cutter is rigidly attached to the side plates. A bracket is welded to the rack; this bracket has longitudinal grooves for attaching the seed guide with a bolt. The seed guide is installed in the area between the plates and consists of two parts: the top and the bottom ones. A plate is welded to the top part of the tube; the plate is used for attaching the tube to the bracket. Top and the bottom parts of the tube are connected with a clutch. The fertilizer guide is attached directly to the rack. This allows sealing seeds and fertilizers to different soil horizons.

The second variant of the colter is different from the first variant of the colter in the fact that, it has a seed guide and a soil compactor. The compactor compacts the layer of soil between the fertilizers and the seeds. The seed guide places seeds closer to the soil compactor, which increases the evenness of seeding. The offered upgrade increases the efficiency of fertilizers in the initial period of plant development and increases the level of crops yield in dry years.

\section{METHODS}

For obtaining the final results, all stages of research have been performed. The area of research has been chosen, the scientific and technical problem has been determined, theoretical and experimental research has been performed, and conclusions about the results of the scientific work have been made.

For energy assessment of the seeder with an improved colter for separate introduction of seeds and fertilizers, an analytic model has been created, and theoretical dependencies of the seeder's tractive resistance have been obtained. ASZSTS-2.0 seeder with standard shovel-type colters was the reference.

Generally, according to the design, the full tractive resistance of standard seeders is determined by the following formula [7] (Aduov, Kapov, Nukusheva, Kaspakov \& Volodja (2017)):

$$
R=G \cdot f+\sqrt[3]{\frac{D^{4}}{b \cdot q \cdot d^{2}}}+h \cdot b \cdot n \cdot\left(K_{m}+K_{p}+K_{k}\right)_{, \mathrm{kN}}
$$


The tractive resistance of the experimental seeder with colters for separate introduction of seeds and fertilizers is determined by the formula following [7] (Aduov, Kapov, Nukusheva, Kaspakov \& Volodja 2017):

$$
\begin{aligned}
R=G \cdot f+\sqrt[3]{\frac{D^{4}}{b \cdot q \cdot d^{2}}} & n \cdot\left[h \cdot b \cdot\left(K_{m}+K_{p}+K_{k}\right)+\right. \\
& \left.+2 h_{l} \cdot b_{l} \cdot\left(K_{l m}+K_{l p}+K_{l k^{\prime}}\right)\right]
\end{aligned}
$$

For energy and agronomic assessment of the seeders with experimental and standard colters, a methodology has been created for performing laboratory and field tests of the developed seeder. The influence of the working speed of the seeder $(V=6.8,10$ and $12 \mathrm{~km} / \mathrm{h})$ and of the seeding depth of the colters $(h=5,7$ and $10 \mathrm{~cm})$ on the tractive resistance of the seeder has been studied. The conditions of the tests were determined, and the agrotechnical and energy performance was assessed in accordance with state standards of the RK. A measuring information system IP 264 with module MS-5 was used for recording and processing experimental data [7] (Aduov, Kapov, Nukusheva, Kaspakov\&Volodja, 2017).

\section{RESULTS AND DISCUSSIONS}

The laboratory and field tests were performed on the territory of the scientific-experimental campus of the University, and the Guldana farm. An experimental unit consisting of a tractor and a seeder with experimental colters was tested. For sowing, wheat variety Astana was used, mineral fertilizer was ammophos, and the reference sowing was made with a standard SZSTS-2.0 seeder. The seeding rate in both cases was $120 \mathrm{~kg} / \mathrm{ha}$, the rate of fertilizer was $30 \mathrm{~kg} / \mathrm{ha}$, the depth of fertilizer introduction in the experimental sample was $7 \mathrm{~cm}$, and the depth of seeds placing was $5 \mathrm{~cm}$; in the reference variant, seeds and fertilizers were introduced to the depth of $5 \mathrm{~cm}$.

The results of theoretical calculations are designated as $\left(\mathrm{R}_{\mathrm{T}}\right)$, the results of experimental studies with a sowing unit consisting of tractor Belarus $952+$ SZSTS-2.0 seeder with standard shovel-type colters- $\left(\mathrm{R}_{\mathrm{e}}^{1}\right)$, and of those with colters for separate seed and fertilizer introduction $-\left(\mathrm{R}_{\mathrm{e}}^{2}\right)$; the background of the field was stubble, the data are shown in Table 1.

\begin{tabular}{|c|c|c|c|c|c|c|c|c|c|c|}
\hline 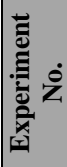 & :气 & 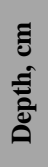 & 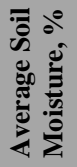 & 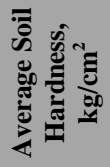 & 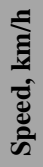 & 预 & 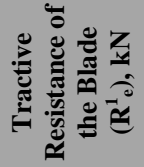 & 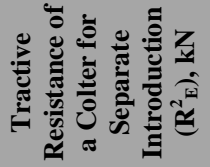 & 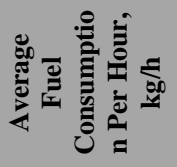 & 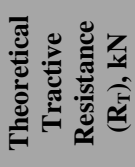 \\
\hline \multirow{4}{*}{1} & \multirow{12}{*}{$\begin{array}{l}\text { Tractor Belarus } 952 \\
+ \text { SZSTS- } 2.0 \text { seeder } \\
\text { with colters (a blade } \\
\text { and a colter for } \\
\text { separate } \\
\text { introduction of } \\
\text { seeds and } \\
\text { fertilizers) }\end{array}$} & \multirow{4}{*}{4} & \multirow{4}{*}{5.6} & \multirow{4}{*}{138} & 6 & 5.57 & 7.264 & 7.41 & 19.09 & 7 \\
\hline & & & & & 8 & 7.9 & 8.561 & 8.90 & 23.443 & 7.56 \\
\hline & & & & & 10 & 9.51 & 9.33 & 9.80 & 17.258 & 8.35 \\
\hline & & & & & 12 & 11.6 & 11.49 & 12.18 & 18.951 & 10.52 \\
\hline \multirow{4}{*}{2} & & \multirow{4}{*}{7} & \multirow{4}{*}{37} & \multirow{4}{*}{267} & 6 & 5.74 & 7.602 & 7.83 & 20.196 & 7.10 \\
\hline & & & & & 8 & 7.74 & 8.65 & 9.07 & 23.104 & 8.49 \\
\hline & & & & & 10 & 9.84 & 8.492 & 11.29 & 17.723 & 10.25 \\
\hline & & & & & 12 & 10.91 & 11.78 & 12.49 & 19.156 & 12.00 \\
\hline \multirow{4}{*}{3} & & \multirow{4}{*}{10} & \multirow{4}{*}{49.4} & \multirow{4}{*}{348} & 6 & 5.81 & 8.294 & 8.54 & 21.965 & 8.2 \\
\hline & & & & & 8 & 7.78 & 8.894 & 10.00 & 23.365 & 8.9 \\
\hline & & & & & 10 & 9.6 & 9.187 & 10.80 & 19.67 & 10.3 \\
\hline & & & & & 12 & 11.6 & 12.06 & 12.90 & 21.065 & 12.30 \\
\hline
\end{tabular}

Table 1: The Results of Theoretical Calculations $\left(\mathbf{R}_{T}\right)$ and Experimental Studies $\left(\mathbf{R}^{1}{ }_{E}\right.$ and $\left.\mathbf{R}_{E}{ }_{E}\right)$

The results of energy assessment of the operation of the sowing unit with different types of working organs, compared to the theoretical dependences in the form of diagrams, are shown in Figures 1-5. 
Analysis of Figure 1 shows that when the tillage depth is $a=4 \mathrm{~cm}$ and the operating speed of the unit changes from $5.57 \mathrm{~km} / \mathrm{h}$ to $11.6 \mathrm{~m} / \mathrm{s}$, the theoretical tractive resistance of the seeder $\left(\mathrm{R}_{\mathrm{T}}\right)$ increases from $7.0 \mathrm{kN}$ to $10.52 \mathrm{kN}$. With that, the operating speed $\mathrm{V}$ of the unitincreases more than twice, and value $\mathrm{R}_{\mathrm{T}}$ increases by $50 \%$. The results of processing the experimental points show that they are approximated by a polynomial dependence of the second order $\left(\mathrm{R}_{\mathrm{e}}^{1}\right.$ and $\left.\mathrm{R}_{\mathrm{e}}^{2}\right)$ with the veracity of $\mathrm{R}^{2}=0.99$. When the operating speed of the unit changes within the specified limits, the value of experimental tractive resistance of a seeder with standard shovel-type colters $\left(\mathrm{R}_{\mathrm{e}}^{1}\right)$ increases from $7.26 \mathrm{kNto} 11.49 \mathrm{kN}$, which is about $60 \%$.

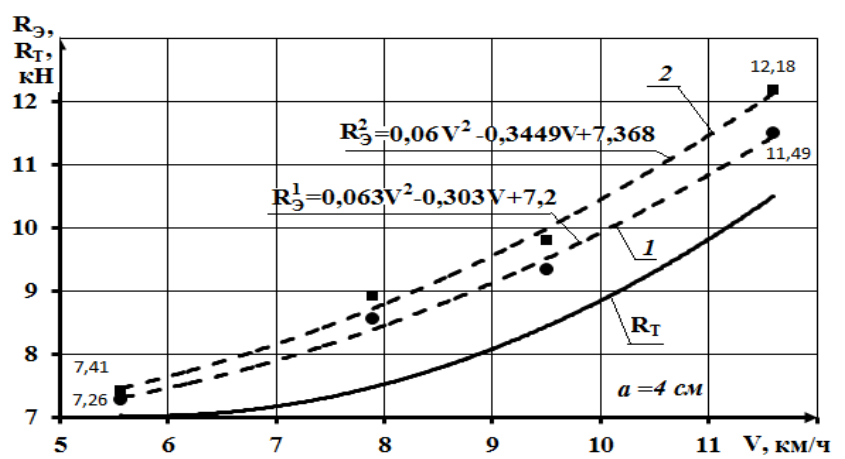

Figure 1: Theoretical $\left(R_{T}\right)$ and Experimental Dependencies of the Tractive Resistance of the SZSTS-2.0

Seeder with Standard Shovel-Type $\operatorname{Colters}\left(\mathbf{R}_{\mathrm{e}}{ }^{1}\right)$ and Colters for Separate Introduction of Seeds and Fertilizers $\left(R_{E}^{2}\right)$ on the Operating Speed $V$ of the Unitwith the Tillage Depth of $a=4 \mathrm{~cm}$

The data for the seeder with colters for separate introduction of seeds and fertilizers are similar, value $R_{E}^{2}$ increases from $7.41 \mathrm{kN}$ to $12.18 \mathrm{kN}$, which is over $64 \%$. In general, the growth percentage for values $\mathrm{R}_{E}^{1}$ and $\mathrm{R}_{E}^{2}$ is the same, and the difference between them is about $4 \%$. Note that with increasing the operating speed of the unit $V$, the difference between the theoretical $R_{T}$ and experimental $\left(\mathrm{R}_{\mathrm{E}}^{1}\right.$ and $\left.\mathrm{R}_{\mathrm{E}}^{2}\right)$ tractive resistance increases.

Similar results were obtained for the tillage depth of $a=7 \mathrm{~cm}$ (Figure 2) and $a=10 \mathrm{~cm}$ (Figure 3). For instance, when the operating speed of the unit changes from $5.74 \mathrm{~km} / \mathrm{h}$ to $10.91 \mathrm{~km} / \mathrm{h}$, and from $5.58 \mathrm{~km} / \mathrm{h}$ to $11.6 \mathrm{~km} / \mathrm{h}$, respectively, for the tillage depth of $a=7 \mathrm{~cm}$ and $a=10 \mathrm{~cm}$, the theoretical $\left(\mathrm{R}_{\mathrm{T}}\right)$ and experimental $\left(\mathrm{R}_{\mathrm{E}}^{1}\right.$ and $\left.\mathrm{R}_{\mathrm{E}}^{2}\right)$ tractive resistances of the seeder increase on average by $6-8 \%$. With that, the difference between the theoretical and experimental tractive resistance does not change much, and averages around $5 \%$.

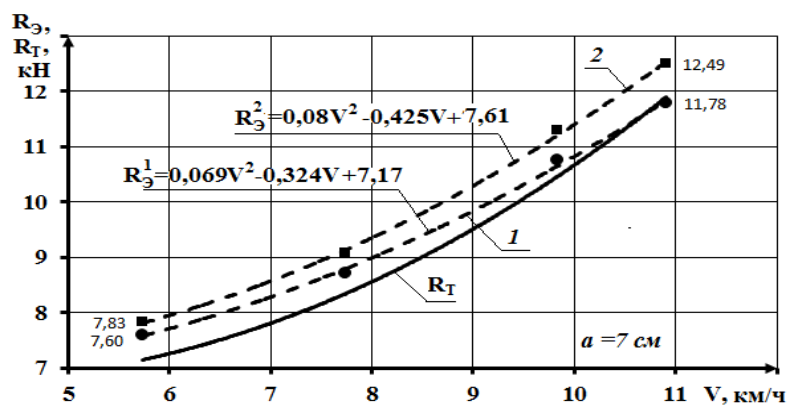

Figure 2: Theoretical $\left(R_{T}\right)$ and Experimental Dependencies of the Tractive Resistance of the SZSTS-2.0 Seeder with Standard Blade-Type Colters $\left(\mathbf{R}_{\mathrm{e}}{ }_{\mathrm{e}}\right)$ and Colters for Separate Introduction of Seeds and Fertilizers $\left(R_{E}^{2}\right)$ on the Operating Speed $V$ of the Unitwith the Tillage Depth of $a=7 \mathrm{~cm}$ 


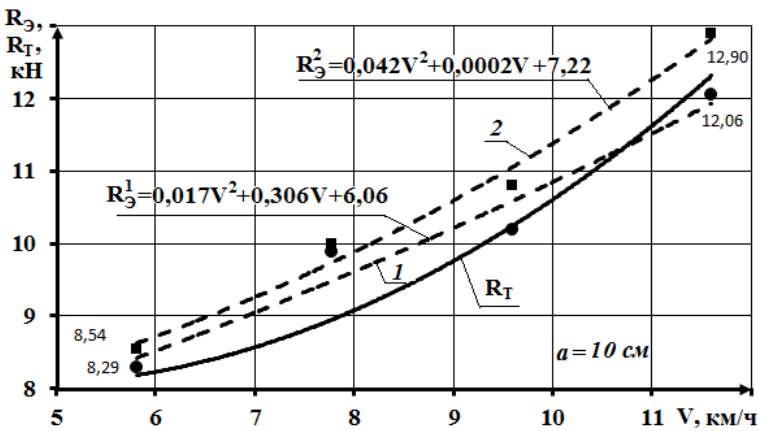

Figure 3: Theoretical $\left(R_{T}\right)$ and Experimental Dependencies of the Tractive Resistance of the SZSTS-2.0 Seeder with Standard Blade-Type $\operatorname{Colters}\left(R_{e}^{1}\right)$ and Colters for Separate Introduction of Seeds and Fertilizers $\left(R_{E}^{2}\right)$ on the Operating Speed $V$ of the Unitwith the Tillage Depth of $a=10 \mathrm{~cm}$

Analysis of the experimental dependences of the seeder tractive resistance on the operating speed $\mathrm{V}$ of the unitwith various tillage depths $a$ (Figure 4) shows that when $V$ is changed on average from $5.81 \mathrm{~km} / \mathrm{h}$ to $11.6 \mathrm{~km} / \mathrm{h}$, it increases twice. With that, the value of dependence $\mathrm{R}_{\mathrm{E}}^{2}$ for curve 1 increases from $8.54 \mathrm{kN}$ to $12.9 \mathrm{kN}$, i.e. on average by $50 \%$. The analysis of Figure 4 (curves 2 and 3) shows that the same pattern is observed in analyzing the experimental data for theseeder with colters for separate introduction of seeds and fertilizers $\left(R_{E}^{2}\right)$.

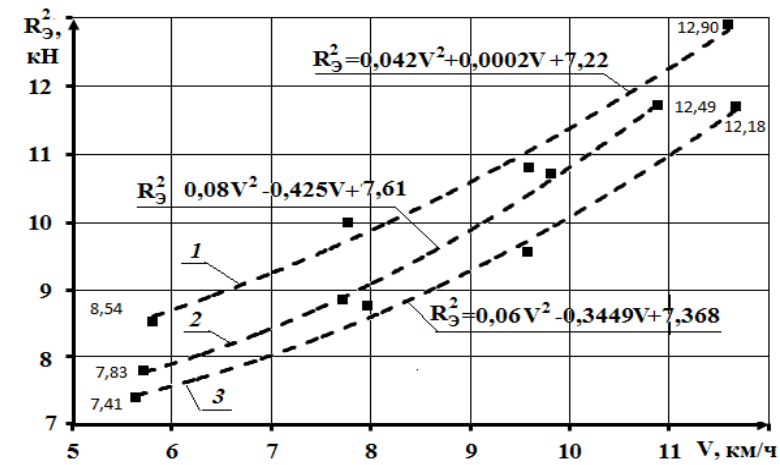

Figure 4: Experimental $\left(\mathbf{R}^{2}\right)$ Dependencies of Tractive Resistance of the SZSTS-2.0 Seeder with Colters for Separate Introduction of Seeds and Fertilizerson the Operating Speed $\mathbf{V}$ of the Unitat Various Tillage Depths: $1-A=10 \mathrm{Cm} ; 2-A=7 \mathrm{Cm} ; 3-A=4 \mathrm{Cm}$

Figure 5 shows in more detail on the influence of the tillage depth on the tractive resistance of the SZSTS-2.0 seeder with colters for separate introduction of seeds and fertilizers $\left(\mathrm{R}_{\mathrm{E}}^{1}\right)$.

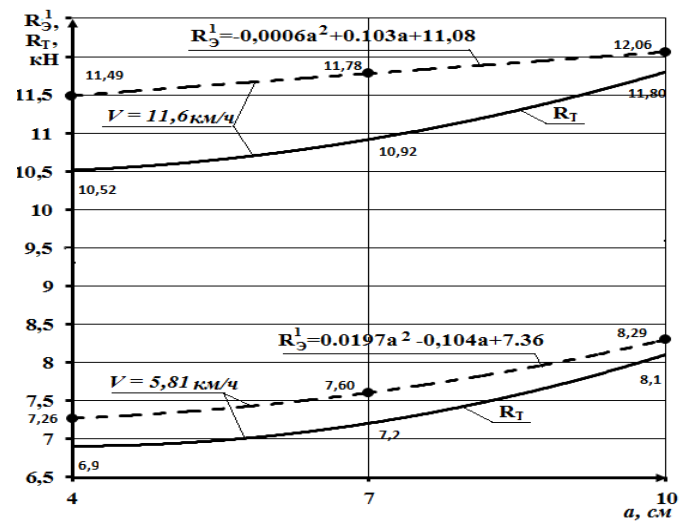

Figure 5: Theoretical $\left(R_{T}\right)$ and Experimental $\left(R_{E}^{1}\right)$ Dependence of the Tractive Resistance of the SZSTS-2.0 Seeder Withcolters for Separate Introduction of Seeds and Fertilizers on the Tillage Depth at Various Operating Speeds Vof the Unit 
For instance, when the tillage depth is $a=4 \mathrm{~cm}$, changing of the operating speed $\mathrm{V}$ of the unitfrom of $5.81 \mathrm{~km} / \mathrm{h}$ to $11.6 \mathrm{~km} / \mathrm{h}$ increases tractive resistances $\mathrm{R}_{\mathrm{T}}$ and $\mathrm{R}_{\mathrm{E}}^{1}$ on average by $0.25 \mathrm{kN}$. Similar results for the tillage depth of $a=10$ $\mathrm{cm}$ show that with increasing the operating speed $\mathrm{V}$ of the unit, the technological process stabilizes, and the share of increasing traction resistances $\mathrm{R}_{\mathrm{T}}$ and $\mathrm{R}_{\mathrm{E}}^{1}$ reduces from $1.2 \mathrm{kN}$ to $0.25 \mathrm{kN}$.

Assessing the agronomic performance of the seeders. Plant density in the experimental plots was counted twice during the vegetation period. The first accounting was made after the full emergence of sprouts and the second one - before harvesting; the data are shown in Table 2.

Table 2: Results of Accounting for Plant Stand Density

\begin{tabular}{|l|c|c|}
\hline \multicolumn{1}{|c|}{ Plot Processed with the Unit } & $\begin{array}{c}\text { The Number of Plants } \\
\text { pcs } / \mathbf{m}^{\mathbf{2}}\end{array}$ & $\begin{array}{c}\text { Field } \\
\text { Germination, \% }\end{array}$ \\
\hline Standard seeder & 214.5 & 85.8 \\
\hline $\begin{array}{l}\text { Seeder with the separate introduction of } \\
\text { seeds and fertilizers (a colter without a } \\
\text { soil compactor) }\end{array}$ & 208.7 & 83.48 \\
\hline $\begin{array}{l}\text { Seeder with the separate introduction of } \\
\text { seeds and fertilizers (a colter with a soil } \\
\text { compactor and a guide) }\end{array}$ & 219.4 & 87.76 \\
\hline
\end{tabular}

Analysis of the table shows that germination on the plot sown with the use of a seeder with an experimental colter without a soil compactor is $83.48 \%$, on a plot planted with the use of the experimental seeder with a soil compactor and guides is $87.76 \%$, and in the reference plot, the germination rate is $85.8 \%$, which means that thecolter without a soil compactor is inferior to the standard one in terms of germination by $2.32 \%$, and thecolter with a soil compactor and a guide is superior to the serial one in terms of germination by $1.96 \%$.

This means that the experimental colter with a soil compactor and a guide creates a dense soil layer between the fertilizer granules and the seeds; the guide places the seeds in this layer, thereby ensuring good contact of seeds and fertilizer granules with the soil.

Table 3 shows the comparative quality indicators of the experimental stubble seed-fertilizer seeder with the separate introduction of seeds and fertilizers, and the standard seed-fertilizer seeder with the introduction of fertilizers to the same horizon.

Table 3: The Comparative Characteristics of the Experimental and the Standard Seeder with the Introduction of Fertilizers to the Same Horizon

\begin{tabular}{|c|c|c|c|}
\hline \multirow{3}{*}{ Indicator Name } & \multicolumn{2}{|c|}{$\begin{array}{c}\text { Seeder with the Separate Introduction of } \\
\text { Seeds and Fertilizers }\end{array}$} & \multirow{2}{*}{$\begin{array}{l}\text { Standard Seeder with the } \\
\text { Introduction of } \\
\text { Fertilizers to the Same } \\
\text { Horizon }\end{array}$} \\
\hline & $\begin{array}{c}\text { A Colter Without a } \\
\text { Soil Compactor }\end{array}$ & $\begin{array}{l}\text { A Colter with a Soil } \\
\text { Compactor and a } \\
\text { Guide }\end{array}$ & \\
\hline & \multicolumn{3}{|c|}{$\begin{array}{c}\text { Date of sowing - May 26, 2017; wheat variety Astana; } \\
\text { Seeder speed }-9.0 \mathrm{~km} / \mathrm{h}\end{array}$} \\
\hline \multicolumn{4}{|c|}{ Seeding Rate, kg/ha } \\
\hline a) predetermined & 120 & 120 & 120 \\
\hline b) actual & 119.8 & 119.5 & 119.6 \\
\hline \multicolumn{4}{|c|}{ Seeding Depth, cm } \\
\hline a) average & 4.54 & 4.61 & 4.46 \\
\hline $\begin{array}{l}\text { b) round mean square } \\
\text { deviation, } \pm \mathrm{cm}\end{array}$ & 0.51 & 0.24 & 0.39 \\
\hline c) coefficient of & 6.76 & 5.2 & 8.76 \\
\hline
\end{tabular}



Introduction of Seeds and Fertilizers

\begin{tabular}{|l|c|c|c|}
\hline variation, \% & & \\
\hline $\begin{array}{l}\text { d) seeds planted to the } \\
\text { layer of middle actual } \\
\text { depth and two adjacent } \\
\text { layers, \% }\end{array}$ & 100 & 100 & 100 \\
\hline & Plants' Distribution across the Feeding Area & \\
\hline $\begin{array}{l}\text { a) average number of } \\
\text { plants in the five- } \\
\text { centimeter section of a } \\
\text { row, pieces }\end{array}$ & 3.45 & 3.48 & 3.29 \\
\hline $\begin{array}{l}\text { b) round mean square } \\
\text { deviation, } \pm \text { pcs }\end{array}$ & 2.34 & 2.31 & 2.28 \\
\hline $\begin{array}{l}\text { c) coefficient of } \\
\text { variation, \% }\end{array}$ & 67.8 & 66.3 & 69.3 \\
\hline
\end{tabular}

Analysis of the table shows that the number of seeds planted to the layer of middle actual depth and two adjacent layers by seeders with experimental and standard colters is the same. Unevenness of the seeding depth for the seeder with standard colters is $8.76 \%$, for the seeder with colters without a compactor $-6.76 \%$, and for the seeder with colter fitted with a compactor and a guide $-5.2 \%$, i.e. thecolter with a compactor and a guide is superior in terms of evenness of seed planting to the standard colter by $3.56 \%$, and the experimental colter without a compactor is superior to the standard colter by $1.56 \%$. In terms of the plant distribution across the area, thecolter with a compactor and a guide is superior to the experimental colter without a compactor by $1.5 \%(66.3 \%$ and $67.8 \%)$, and to the standard colter- by $3 \%(66.3 \%$ and $69.3 \%)$.

Table 4 shows the structure of wheat yield for the experimental and standard seeders with the introduction of fertilizers to the same horizon.

Table 4: The Structure of Wheat Yield in the Experimental Plots in 2017

\begin{tabular}{|l|c|c|c|c|c|c|c|}
\hline $\begin{array}{l}\text { Experimental } \\
\text { Plots }\end{array}$ & $\begin{array}{c}\text { Number } \\
\text { of Plants, } \\
\text { pcs/m }\end{array}$ & $\begin{array}{c}\text { Plant } \\
\text { Height, } \\
\text { cm }\end{array}$ & $\begin{array}{c}\text { Spike } \\
\text { Length, } \\
\text { cm }\end{array}$ & $\begin{array}{c}\text { Number of } \\
\text { Grains Per } \\
\text { Spike, Pcs }\end{array}$ & $\begin{array}{c}\text { The Weight } \\
\text { of Grains } \\
\text { Per Spike, g }\end{array}$ & $\begin{array}{c}\text { The Weight } \\
\text { of 1,000 } \\
\text { Grains, g }\end{array}$ & $\begin{array}{c}\text { Yield } \\
\text { Rate, } \\
\text { t/ha }\end{array}$ \\
\hline $\begin{array}{l}\text { Standard } \\
\text { seeder }\end{array}$ & 304.4 & 52.53 & 6.5 & 24.2 & 0.77 & 28.86 & 16.67 \\
\hline $\begin{array}{l}\text { Experimental } \\
\text { seeder fitted } \\
\text { with colters } \\
\text { without soil } \\
\text { compactors }\end{array}$ & 326.6 & 57.14 & 6.8 & 23.7 & 0.79 & 29.83 & 19.296 \\
\hline $\begin{array}{l}\text { Seeder fitted } \\
\text { with } \\
\text { experimental } \\
\text { colters with } \\
\text { soil } \\
\text { compactors } \\
\text { and guides }\end{array}$ & 319.8 & 55.51 & 6.8 & 23.9 & 0.79 & 31.20 & 21.3 \\
\hline
\end{tabular}

Analysis of Table 4 shows that the number of productive stems in the experimental plots exceeds the number of productive stems in the reference plot $(326.6 ; 319.8$ and 274.8), and the weight of grains in a spike in the experimental plots is higher than the weight of grains in a spike in the reference plot $(0.79,0.79$, and $0.77 \mathrm{~g})$. Accordingly, the yield in the experimental plot sown with the seeder fitted with a colter without a soil compactor is $19.296 \mathrm{hw} / \mathrm{ha}$, and in the plot sown with the seeder fitted with a counter with a compactor and a guide $-21.3 \mathrm{hw} / \mathrm{ha}$, while in the reference plot it is 
$16.67 \mathrm{hw} / \mathrm{ha}$; thus, the increase in the yield is from $2.63 \mathrm{t} / \mathrm{ha}$ to $4.63 \mathrm{t} / \mathrm{ha}$ (15.8\% and $27.8 \%)$. The increase in the yield is explained by the fact that this year's June was dry, and roots of the plants in the reference plot did not use the fertilizer located in the same horizon and spread deeper into the soil. In the experimental plot, the experimental colterhad placed the fertilizers 2 cmbelow the seeds, and the plants efficiently used the startup dose of fertilizers. Similar results in wheat yield were obtained in the experimental plots for 3 years $(2015-2017)$.

The economic efficiency of the experimental seeder was assessed by comparing the cost efficiency and the yield growth. The adjusted costs and specific capital costs for the standard and the experimental seeders were slightly different, and the annual economic effect from the use of the seeder with the experimental colterswas achieved due to increasing the yield of cultivated crop, and amounted to $1,475,710$ tenge.

\section{CONCLUSIONS}

Based on the foregoing, the following conclusions can be made

Theoretical and experimental dependencies of the tractive resistance have been obtained for the experimental seeder fitted with colters for separate introduction of seeds and fertilizers on the depth of seeds' planting and the working speed;

Tractive resistance of the experimental seeder with colters for separate introduction of seeds and fertilizers exceeds the tractive resistance of the SZSTS-2.0 seeder with standard shovel-type colters by $5-10 \%$ in the stubbles, and by $1.5-5 \%$ in a plowed field;

In terms of the quality of operation, the seed-fertilizer seeder for stubbles with the separate introduction of seeds and fertilizers is superior to the standard seed-fertilizer seeder for stubbles: in terms of the evenness of seeding - by 3.56 $\%$; in terms of plant distribution across the feeding area - by $3 \%$;

The yield in the experimental plot sown with the seeder fitted with a colter without a soil compactor is 19.296 hw/ha, and in the plot sown with the seeder fitted with a colter with a compactor and a guide $-21.3 \mathrm{hw} / \mathrm{ha}$, while in the reference plot it is $16.67 \mathrm{hw} / \mathrm{ha}$; thus, the increase in the yield is from $2.63 \mathrm{t} / \mathrm{ha}$ to $4.63 \mathrm{t} / \mathrm{ha}(15.8 \%$ and $27.8 \%)$. The estimated annual economic effect from the use of the developed seeder amounts to 1,475,710 tenges.

\section{ACKNOWLEDGEMENTS}

The research was performed in the framework of the State Target Budget Program 255 "Creation of the Conditions for Development of Production, Processing and Sales of Crop Products" according to the scientific and technical program "Development of Modern Farming Systems for Various Soil-and-Climatic Zones of Kazakhstan" on topic "A seed-fertilizer seeder for the stubbles with separate introduction of seeds and fertilizers" of the Ministry of Agriculture of the Republic of Kazakhstan, contract No. 09-z.

\section{REFERENCES}

1. M.I.Matiouchkov, N.K.Azarov, Mashinyitekhnologiivozdelyvaniiazernovykhkultur pripochvozashchitnoisistemezemledeliia [Machines and technologies for cultivating grain crops in a conservation cropping system] -Shortandy: Booklet. $-2002 .-$ pp. $6-7$.

2. Aduov M A, Kapov $S$ N, \&Nukusheva $S$ A (2017).The influence of random technological and control impacts on the process of seed sowing and mineral fertilizers. Eco. Env. \& Cons. $23(1): 267-277$. 
3. Çelik A \&Altikat S (2013). Seeding Performances of No-Till Seeders Equipped with Different Furrow Openers, Covering Components and Forward Speeds for Winter Wheat. Research Article - Agricultural Technologies. pp.226-239.

4. Kryhcin N. P. (2003). Sowing machines. In: Features of structures and development trends. OAO "SamVen-Kinel", Kinel, pp $116-118$.

5. AMALIYAR, K. R. (2016). A Study On Market Potential, Farmers'buying Behaviour, And Satisfaction Level Towards Water Soluble Fertilizers In Anand And Narmada Districts(Doctoral dissertation, Anand Agricultural University, Anand).

6. Aduov M A, Kapov $S$ N, Nukusheva $S$ A, Kaspakov E G \&Volodja K. (2017). The results of the laboratory and field tests of seeders with combined ploughares. International scientific journal Mechanization in agriculture. Issue No. 2: 60-63.

7. Aduov M A, Kapov S N, Nukusheva S A, Kaspakov E G \&Volodja K. The Republik of Kazakhstan Patent No. 32031 Colter bulletin No. 9 dated 15.05.2017.

8. Aduov M A, Kapov S N, \& Nukusheva S A (2016).Seed drill with colters in the technology of separate sowing and fertilizer introduction International scientific journal. Mechanization in agriculture. Issue No. 1: 12-14. 
